Disponível em

http://www.anpad.org.br/rac

RAC, Curitiba, v. 15, n. 5, art. 1, pp. 794-814, Set./Out. 2011

$(\mathrm{cc})$ EY-NC

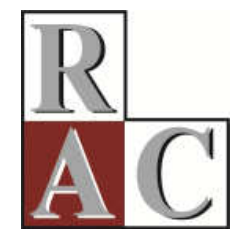

\title{
Implicações da Aprendizagem Experiencial e da Reflexão Pública para o Ensino de Pesquisa Qualitativa e a Formação de Mestres em Administração
}

\section{Experiential Learning and Public Reflection: Implications for Scientific Research Teaching and Masters Development in Management Education}

Beatriz Quiroz Villardi * E-mail: bqv2008@ufrrj.br Universidade Federal Rural do Rio de Janeiro - UFRRJ Rio de Janeiro, RJ, Brasil.

Sylvia Constant Vergara E-mail: sylvia.vergara@fgv.br Fundação Getúlio Vargas -EBAPE/FGV

Rio de Janeiro, RJ, Brasil.

* Endereço: Beatriz Quiroz Villardi

Rodovia BR 465, Km 7, s/n, Seropédica, Rio de Janeiro/RJ, 23890-000.

Copyright (C) 2011 RAC. Todos os direitos, até mesmo de tradução, são reservados. É permitido citar parte de artigos sem autorização prévia, desde que seja identificada a fonte. 


\title{
Resumo
}

Na pós-graduação stricto sensu em Administração se formam professores e pesquisadores. Esperamos que os mestrandos desenvolvam sua capacidade de aprendizagem para realizar pesquisas. A procrastinação acadêmica e o choque de aprendizagem dos mestrandos, no entanto, dificultam esse processo. O estudo exploratório aqui apresentado se propôs a examinar a prática de ensino-aprendizagem durante e após o processo de aprender a pesquisar, buscando resposta para a seguinte questão: como mestrandos aprendem, por meio de prática experiencial, a realizar pesquisa qualitativa em administração? Apoiado em referencial teórico que trata de processos de ensino-aprendizagem, reflexão e pesquisa qualitativa, o estudo realizou percurso metodológico inspirado na fenomenologia e na abordagem socioconstrutivista, privilegiando a experiência vivida de professores e alunos. Chegamos à conclusão de que a vivência de pesquisa de campo e a prática de reflexão pública no e sobre o campo: (a) ampliou a consciência dos participantes sobre a sua importância no processo de ensino-aprendizagem; e (b) revelou duas implicações, quais sejam: pode auxiliar docentes de cursos de mestrado em administração na reflexão de suas próprias práticas, e gestores de IES na formulação de políticas para capacitação de docentes e de políticas didático-pedagógicas.

Palavras-chave: aprendizagem experiencial; reflexão pública; ensino de pesquisa qualitativa; procrastinação acadêmica; práticas na formação de mestres de administração.

\begin{abstract}
Stricto sensu postgraduate management education prepares researchers and teachers. We hope that Master's Degree students develop their learning capacity in order to conduct research. Academic procrastination and learning shock on the part of the Master's Degree students hinder this process. The purpose of this exploratory study is to examine the teaching-learning practice during and after the learning-to-research process, seeking to answer the following question: How do Master's Degree students learn through actual experience while conducting qualitative research on management related issues? Based on a theoretical reference related to teaching-learning, reflection and qualitative research, the study traced a methodological trajectory inspired by phenomenology and the socio-constructivist approach that favor a better experience for professors and students. We reached the conclusion that the experience of field research and the practice of public reflection in an on the field (a) increased the awareness of the participants concerning their importance in the teaching-learning process and (b) revealed two implications: it can help teaching staff in Master's Degree courses in management to reflect on their own practices and it can help Master's Degree managers to formulate policies for preparing staff and didactic-pedagogical policies.
\end{abstract}

Key words: experiential learning; public reflection; qualitative research teaching; academic procrastination; management of Master's Degree education practices. 


\section{Introdução}

$\mathrm{Na}$ pós-graduação stricto sensu, na qual se formam professores e pesquisadores de administração, espera-se, em um prazo de 24 meses, que os estudantes de mestrado desenvolvam sua capacidade de abstração e ação para pesquisar, de modo a construir conhecimento científico em administração. Entretanto a complexidade deste processo de aprendizagem parece não ter sido considerada pelos métodos de ensino e pesquisa nem pelos projetos político-pedagógicos predominantes, originários da tradicional epistemologia positivista que ainda parece orientar a formação acadêmica nos cursos de mestrado de administração.

Desde a graduação, não é raro perceber-se que o curriculum vigente nas escolas de administração no Brasil considera que os estudantes trabalharão em empresas orientadas pelos princípios de gestão propostos por Taylor e Fayol no início da sociedade industrial, quando predominavam ambientes menos competitivos e mercados menos complexos. Foi o que alertou Nicolini (2003). Para ele, nas práticas docentes das escolas de administração o taylorismo se revela em disciplinas, cujos conteúdos e foco do ensino estão apoiados em uma concepção bancária da educação, nos termos de Freire (1967).

Na pós-graduação stricto sensu, no que se refere à pesquisa, de modo geral, mestrandos vão aprendendo a pesquisar principalmente de modo individual, com base na exposição de seus professores, algumas vezes com aulas dinamizadas por estudos de caso, pseudosseminários e grupos de discussão virtual criados por iniciativa dos alunos. Dessa forma, parece que esse aprendizado é suficiente para que, depois de formados mestres de administração, tais alunos estejam habilitados a lecionar em cursos de graduação. No entanto, pareceu-nos que esse posicionamento deve ser revisto. Assim, refletimos sobre seus pressupostos e os da aprendizagem experiencial e formulamos a questão que desencadeou o estudo: como mestrandos aprendem, por meio de prática experiencial, a realizar pesquisa qualitativa em administração?

A pesquisa aqui apresentada faz parte de uma investigação interinstitucional mais ampla, que está sendo desenvolvida por nós, autoras, e a apresentação estrutura-se da seguinte forma: revelação da decisão didático-pedagógica para a realização do estudo, sua relevância, percurso metodológico, o contexto da pós-graduação no Brasil; reflexões sobre o processo de ensino e aprendizagem e sobre a pesquisa qualitativa em administração, a entrevista como método de coleta de dados no campo, entrevistando no campo e sobre ele refletindo. Por fim, são apresentadas conclusões e implicações do estudo para a formação de mestrandos de administração, assim como são levantadas questões para futura pesquisa.

\section{A Revelação de uma Decisão Didático-Pedagógica}

A pesquisa aqui apresentada revela uma decisão didático-pedagógica tomada por duas professoras em duas IES, uma privada e outra pública, ambas no Estado do Rio de Janeiro, a partir dos comportamentos dos alunos calouros. Eles começavam entusiasmados a cursar as disciplinas de seu curso; mas já nas disciplinas obrigatórias, como Metodologia da Pesquisa, apresentavam dificuldades em seu desempenho, que se revelavam em sala de aula pelas discussões e trabalhos escritos apresentados numa lógica mais reprodutiva que crítica, tendência a pedir 'mais prazo' para entregar seus trabalhos e preferência por trabalhos em grupo à prova individual como forma de avaliação da aprendizagem.

Justificavam seus pedidos pela forte carga de leitura de cada disciplina, falta de tempo, não familiaridade com a área de administração, disciplinas mais difíceis. Iniciava-se, assim, uma prática de procrastinação, que indicava a nós, professoras de Metodologia da Pesquisa, um possível choque de aprendizagem, como definido por Griffiths, Winstanley e Gabriel (2005). Nos mais 
jovens, talvez se devesse à pouca experiência de trabalho profissional e à expectativa do mestrado ser uma continuidade da formação de graduação só com mais leitura; nos mais velhos, parecia resultar de sua maior experiência de trabalho e afastamento dos estudos formais: há muito tempo que fiz minha monografia [na graduação].

Procrastinação acadêmica refere-se, segundo Soloman e Rothblum (1984 como citado em Orpen, 1998), a uma tendência a postergar tarefas relativas aos estudos de modo que elas não são realizadas nas datas solicitadas, ou são feitas apressadamente somente para entregá-las aos professores. As consequências da procrastinação no desempenho acadêmico e nas atitudes de estudantes procrastinadores em relação às disciplinas e professores associam-se, de acordo com Orpen (1998), a três tipos de motivação dos alunos: à extrinsecamente regulada, aquela determinada por recompensas e castigos de outrem; por exemplo, estudo porque senão meus pais se aborrecem; à motivação instrumental, voltada ao cumprimento de metas, por exemplo, estudo para tirar as notas necessárias para formar-me, e à intrínseca, isto é, determinada por sentimentos positivos derivados do estudo das disciplinas por sua própria iniciativa; por exemplo, preciso realmente entender os temas que estudo.

Entendemos, com Orpen (1998), que o termo choque de aprendizagem refere-se à frustração, confusão e ansiedade vivenciadas por alguns estudantes, quando expostos a métodos não familiares de aprendizagem e ensino que podem levá-los a se sentirem pressionados por demandas inesperadas e desestruturadoras, em ambientes contrastantes e com expectativas diferenciadas.

Nós, autoras do presente trabalho, reconhecemos que nossa prática de ensino da disciplina em sala de aula estava circunscrita às leituras prévias e dinâmicas para discussão em grupo, com ênfase em abstração. Também reconhecemos que, além das disciplinas obrigatórias, os mestrandos passam pelo processo de orientação para a elaboração de dissertação, o que igualmente demanda mais pensamento crítico e capacidade de pesquisa; segundo nós, estes não seriam alcançados apenas pelo estudo na disciplina e nas leituras recomendadas pelos respectivos orientadores. Apercebemo-nos também de que, no processo de orientação, os orientadores consideravam que os fundamentos de metodologia da pesquisa científica tinham sido aprendidos pelo aluno; daí se limitarem a fornecer listas de textos para leitura de seus orientandos e discussões localizadas e esporádicas, muitas vezes só quando solicitadas pelos próprios orientandos. Desse modo, os mestrandos somente aplicavam os conceitos quando iam a campo depois da qualificação do projeto de dissertação que ocorre, geralmente, no final do primeiro ano de estudo. Efetivamente, somente no campo objeto de sua pesquisa para dissertação, os mestrandos se deparavam com as dificuldades de cada fase da metodologia de pesquisa proposta no projeto para levantar dados empíricos e tratar delas.

Procrastinar e entrar em choque de aprendizagem era indesejável, em nossa opinião, porque isso impactaria, ao longo do curso, na qualidade da formação dos mestrandos e de suas dissertações. Portanto, prevenir baixo desempenho acadêmico e dar aos alunos a oportunidade de elaborarem dissertações de qualidade pela capacidade em pesquisa cientifica de administração pareceu urgente a nós, professoras da disciplina Metodologia da Pesquisa, também orientadoras nestes cursos de mestrado.

$\mathrm{Na}$ busca por formas de mudar nossas práticas de ensino recorremos a estudos e aplicamos conceitos dentro do conhecimento cientifico da administração sobre aprendizagem coletiva, especificamente aprendizagem pela experiência e aprendizagem reflexiva. Decidimos, assim, utilizar métodos de ensino de metodologia cientifica diferentes. Pretendíamos propiciar aos nossos alunos o desenvolvimento de aprendizagem com perspectiva crítica, que parece ainda não prevalecer no cenário atual do ensino em administração.

Chanlat (1996, p. 24) já denunciara, na formação do administrador, quando afirma: "elevado grau de especialização, rigidez, ausência de consciência critica, quantitativismo, economicismo, ausência de consciência histórica e inaptidão para comunicar ou interagir nos programas e no comportamento dos estudantes". Sendo a administração uma prática e área de conhecimento científico reconhecida, é de se esperar que utilize pesquisa cientifica para construir conhecimento visando 
formação crítica do administrador. Nesse esforço, Aktouf (1996, p. 148) ressalta a capacidade de reflexão do gestor para orientar essa prática: "Refletindo a experiência vivida [o gestor] esclarece sua percepção das situações e melhor funda as intuições que o guiarão no exercício de sua atividade". No entanto pouco tem mudado nesse cenário para fazer da reflexão e da pesquisa sistematizada uma prática discente.

Nós, professoras, também refletimos na proposta de Freire (2000). Percebemos juntas as limitações de nossas práticas de ensino e orientações de dissertações e decidimos propor processos de aprendizagem pela vivência e reflexão, para desenvolver nos mestrandos competências de pesquisa adequadas e estimular sua autonomia intelectual, dando-lhes a oportunidade de transformação de uma consciência ingênua para uma consciência, crítica por meio da participação efetiva no projeto de pesquisa qualitativa em andamento fora da sala de aula. A consciência ingênua refere-se ao grau mais elementar da consciência que percebe os fenômenos, mas não sabe como julgá-los, devido a um desconhecimento da raiz da realidade, enquanto a consciência crítica é relativa a uma profunda interpretação da realidade, de seus princípios causais e conhecimento do seu funcionamento. Ela é alcançada pelo diálogo e pelo compromisso na construção de mudança.

Por meio de pesquisa de nossa própria prática de ensino dos fundamentos de metodologia científica, procuramos responder a vários questionamentos que emergiam: Como, no curto prazo, ensinar os fundamentos de pesquisa científica a alunos calouros? Como, ao aprender a realizar pesquisa qualitativa dos fenômenos organizacionais os alunos reconhecem a subjetividade e a necessária intersubjetividade para entrevistar no campo? Como propiciar entre alunos e professores reflexão, autocrítica e aprendizagem coletiva sobre pesquisa qualitativa de administração?

Para respondê-las, nós, professoras aproveitamos uma pesquisa interinstitucional mais ampla daquela que estávamos realizando e convidamos alunos calouros, nela estavam interessados, para, juntos, participarem. Nosso propósito era expor esses mestrandos a uma vivência extraclasse de uma pesquisa acadêmica real em andamento, na qual efetivamente elaborassem um roteiro para entrevistar no campo e selecionassem métodos para a análise dos dados empíricos coletados, conceitos que estavam estudando na disciplina e que permitiriam elaborar seu projeto de pesquisa de dissertação. Este é o estudo que aqui apresentamos.

\section{Relevância do Estudo Realizado}

Reunir, sistematizar e compartilhar resultados de aprendizagem com base empírica dos processos de pesquisa qualitativa poderá subsidiar a elaboração de aulas mais especificas, que considerem as dificuldades de aprendizagem no processo ensino-aprendizagem de metodologia de pesquisa, tanto dos alunos quanto dos professores. Poderá subsidiar docentes de cursos de mestrado de administração na reflexão de suas próprias práticas, na elaboração do programa da disciplina e planos de aula. Cursos de mestrado e seus professores de Metodologia também podem beneficiar-se desta sistematização de requisitos do aprender a pesquisar que, pelo detalhamento alcançado, permite a operacionalização no elaborar e organizar seus projetos pedagógicos, programas e planos de aula. $\mathrm{O}$ estudo é relevante também porque os resultados empíricos e conceituais, baseados na ação de docentes e na vivência dos discentes, poderão subsidiar a construção de conhecimento e teorização das práticas docentes em cursos de pós-graduação em administração no Brasil, assim como ajudar gestores de IES na elaboração de políticas para a formação de mestres de administração.

A carência de contribuições teóricas que ajudem a superar a escassez de teorização com base empírica nos estudos de aprendizagem organizacional e estudos centrados em micro-práticas foi apontada por Easterby-Smith e Araújo (1999) e, no Brasil por Antonello e Godoy (2009). Estas autoras brasileiras também reconhecem a importância de pesquisar as práticas nas organizações, afirmando que a noção de prática é rica porque articula a noção de espaciotemporal do fazer dos agentes como práticas 'situadas'. Alertam, entretanto, que para obter os insights que esta noção pode 
gerar será necessário repensar os métodos de pesquisa cientifica que são utilizados ao examinar a prática, em função da natureza interpretativa desse processo.

Uma contribuição deste artigo é, também, ilustrar com material empírico, formas e reflexões presentes em um processo de aprendizagem experiencial.

Apresentamos, a seguir, o percurso metodológico do estudo realizado.

\section{A Caracterização do Estudo e o Percurso Metodológico}

Trata-se de estudo empírico-conceitual qualitativo, pois se reconhece a subjetividade no fenômeno aprendizagem coletiva e os indivíduos como sujeitos na pesquisa a serem acompanhados por dentro, não apenas como objetos a serem observados. A epistemologia na qual se fundamenta é a fenomenológica e, portanto, conforme apontaram Morgan e Smircich (1980) ao caracterizar esta vertente da pesquisa qualitativa, neste estudo também foram reconhecidas a subjetividade e intersubjetividade dos envolvidos, - professoras e alunos de mestrado. O estudo é, ainda, episódico nos termos de Hendry e Seidl (2003), pois destaca apenas, como será visto a seguir, um episódio no processo de aprender a pesquisar: a experiência individual de realização de entrevista no campo.

Entre os quarenta e seis alunos que cursavam Metodologia da Pesquisa, quatro calouros dos dois cursos de mestrado de administração aceitaram participar do processo. Os mestrandos, dois homens e duas mulheres, de 28 a 32 anos, são três bacharéis de Administração, um deles também bacharel de Filosofia, e um bacharel de Matemática. Profissionalmente, três deles atuam como servidores públicos federais nas áreas de recursos humanos de suas respectivas organizações, e um deles como professor universitário, havendo também coordenado um Curso de Graduação em Administração. Eles se tornaram membros da equipe do projeto da pesquisa interinstitucional em andamento, cujo objetivo é mapear a aprendizagem coletiva e formação de competências profissionais de docentes em Cursos de Administração.

O período de observação dos alunos, em que trabalhamos nós, professoras se iniciou em julho de 2009 até março de 2010, quando os alunos prepararam relatórios parciais e os compartilharam, publicamente, em três encontros específicos dessa pesquisa. Além dos registros das observações do trabalho cotidiano que a pesquisa envolvia, os mestrandos também participaram de entrevista semiaberta realizada por nós, professoras. Antes e depois das apresentações coletivas como no seu desenrolar, os alunos participantes relatavam seus avanços sobre o seguinte: aplicação dos conceitos estudados acerca da elaboração de um roteiro de entrevista; realização de entrevista exploratória e entrevista piloto que, depois, realizaram. Os depoimentos transcritos foram analisados iterativamente.

Para identificar conceitos que permitissem a análise e a descrição dos processos de aprendizagem e de reflexão coletiva, foi privilegiada a interpretação como abordagem socioconstrutivista. A abordagem socioconstrutivista, de acordo com Easterby-Smith e Araújo (1999), em que se considera: (a) a teorização como prática social dinâmica na qual o conhecimento é desenvolvido; (b) os indivíduos como agentes ativos na aquisição de conhecimento, aprendizes que aprendem de diferentes formas, rotinas e inovações; (c) as práticas pedagógicas também como práticas sociais que requerem avaliação de seus resultados globais; (d) os processos cognitivos como construção social de significados. A abordagem socioconstrutivista também revela, na aprendizagem coletiva e individual, a subjetividade que fundamenta a epistemologia fenomenológica. Esta, no entanto, destaca a construção da realidade pelos indivíduos. Por não considerarmos a impossibilidade de dialogo entre diferentes epistemologias, admitimos o dialogo entre a fenomenologia e a concepção socioconstrutivista. A subjetividade se revela, portanto, como ponte capaz de estabelecer diálogo entre a abordagem socioconstrutivista e a fenomenológica.

Durante a análise das entrevistas com os alunos e os relatórios que nos apresentavam emergiram conceitos como estes: procrastinação acadêmica, choque de aprendizagem, reflexão, reflexividade, 
aprendizagem pela experiência, subjetividade, intersubjetividade, compreensão e entrevista romântica que, uma vez examinados, subsidiaram a elaboração das conclusões e implicações para a formação de mestres pesquisadores de administração. Esses conceitos também permitiram descrever o fenômeno sob estudo, qual seja o processo de aprender de professores e mestrandos ao fazer pesquisa qualitativa e, especificamente, ao entrevistar no campo.

A estrutura deste artigo revela os processos e níveis de reflexão alcançados sobre as ações e conceitos que, iterativamente, emergiam da aprendizagem experiencial iniciada com os alunos de mestrado, portanto, de curso de pós-graduação.

\section{O Contexto da Pós-Graduação no Brasil}

Na década de 60, o Parecer CES/CFE n. 977 (1965) do Conselho Federal de Educação instituiu duas configurações para a pós-graduação stricto sensu e lato sensu. A primeira é de natureza acadêmica e seus cursos de administração cresceram aceleradamente, a partir da década de 1970 . Na década de 90, houve o reconhecimento do mestrado profissional conforme explicitado na Portaria CAPES n. 080 (1998). Pela Resolução CNE/CES n. 1 (2001) estabeleceram-se normas para o funcionamento dos cursos de pós-graduação e em 2003 foi constituída uma Comissão Interministerial composta por membros de suas respectivas instituições de fomento, o Conselho Nacional de Desenvolvimento Científico e Tecnológico (CNPQ) e a Coordenação de Aperfeiçoamento de Pessoal de Nível Superior (CAPES) para o desenvolvimento da pós-graduação pela Portaria Interministerial n. 270 (2003).

Uma pesquisa apresentada por Marques (2008) sobre diagnóstico institucional dos programas de pós-graduação stricto sensu realizada em 2008, pela Fundação Carlos Chagas Filho de Amparo à Pesquisa do Estado do Rio de Janeiro (FAPERJ), em conjunto com a Escola Nacional de Saúde Pública Sergio Arouca e pela Fundação Oswaldo Cruz revelou a diversidade das realidades acadêmica, gerencial e de infraestrutura dos programas e instituições de pós-graduação stricto sensu no Estado do Rio de Janeiro. Tal pesquisa teve como universo de estudo a totalidade dos programas de pósgraduação credenciados pela Coordenação de Aperfeiçoamento de Pessoal de Nível Superior (CAPES), desde o triênio 2004-2006 até julho de 2008.

No final da década de 60, a pós-graduação tinha, aproximadamente, 100 cursos, abrangendo cerca de 2.000 alunos em todo o país. Quatro décadas depois, contava com 2.410 programas, entre mestrados acadêmicos, doutorados e mestrados profissionais, e mais de 130.000 alunos matriculados. A Região Sudeste concentra 51\% da oferta de programas de pós-graduação do País (Marqus, 2008).

No que diz respeito às configurações organizacionais, Fischer, Nicolini e Silva (2005) informam que no Brasil coexistem universidades, centros universitários, escolas, faculdades, fundações. Afirmam que até, 2004, havia 5.872 professores na pós-graduação, não necessariamente ensinando na graduação nem sendo pesquisadores. Muitos são consultores, gestores acadêmicos, orientadores, revisores, provedores de recursos, membros de comissões e representantes institucionais e atuam em variados regimes de trabalho: tempo integral, parcial, por hora, por aula.

Em relação à pesquisa, esses autores consideram que a produção massiva e a qualidade desigual geram publicações que não representam acumulação de resultados de pesquisa. Em relação à pratica de ensino Fischer et al. (2005, p. 110), afirmam que "o professor pode ficar inteiramente isolado em sua disciplina, jamais discutindo conteúdos com colegas da mesma linha curricular".

No Triênio 2007-2009, a Coordenação de Aperfeiçoamento de Pessoal de nível Superior avaliou 96 programas de mestrado de administração com notas de 3 até 7 . Trinta e nove programas obtiveram nota 3 , trinta e seis programas alcançaram nota 4 , dezesseis nota 5, três nota 6 e dois programas obtiveram nota máxima 7 (CAPES, 2011). A leitura dos programas e das atividades de ensino da disciplina de Metodologia da Pesquisa de dez cursos de mestrado, localizados na região sul e sudeste, 
avaliados com nota 5, 6 e 7 pela Capes em 2010, relativamente ao triênio 2007-2009, não nos permitiu perceber a inclusão da reflexão individual e pública para estimular a aprendizagem, nem ênfase na prática de aprendizagem experiencial.

Nossa reflexão sobre a prática de ensino e pesquisa em geral é apresentada a seguir.

\section{O Ensino e o Processo de Aprendizagem}

Aprender as práticas de trabalho em organizações universitárias aproxima a educação da gestão do desenvolvimento de docentes. Neste sentido, Reynolds e Vince (2004) examinaram duas perspectivas de educação e gestão de administração, denominadas: (a) Estudos Críticos de Administração (Critical Management Studies), focada em entender as práticas organizacionais de gestão; e (b) Aprendizagem Baseada na Ação (Action-Based Learning), que foca o processo educacional.

Consideram os autores que a perspectiva de aprendizagem baseada na ação não tem sido suficientemente reconhecida pela comunidade de educação de administração, embora tenha sido desenvolvida como alternativa aos métodos tradicionais de ensino, que retiram do estudante o senso de responsabilidade por seu próprio aprendizado.

Ao realizar estudo empírico da aprendizagem que o ensinar proporciona, Cortese (2005) examinou as ideias de educadores, como Dewey e Freire, ressaltando que ambos consideram as técnicas de ensino um diálogo no qual o professor e o aluno são igualmente livres e críticos, o que os tornam capazes de aprender juntos e conscientes das suas circunstâncias.

Assim, o ensino se torna um processo de duas vias, e o papel tradicional do professor desaparece, porque ambos os indivíduos, conscientes, produzem conhecimento novo para ambos. Pelo diálogo, o professor deixa de ser quem ensina para também ser ensinado por seus estudantes que, por sua vez, ao serem ensinados, também ensinam. Desse modo, tanto Dewey quanto Freire rejeitam a posição tradicional de considerar o aluno um recipiente a ser preenchido ou uma fita a ser gravada pela ação do professor. Este se torna um ponto de partida de um processo de mútua doação, no qual tanto ele quanto o aluno oferecem seu saber e sem medo de receber o saber do outro (Cortese, 2005).

Ao examinar o processo de ensinar em seu estudo empírico com gerentes que ensinam, Cortese (2005) identificou um aspecto especifico que propicia aprender pelo ensino: o encontro com a diversidade que, de um lado, tende a aumentar a reflexão e, de outro, tende a quebrar resistências à mudança. De acordo com o autor, no encontro com a diversidade dos indivíduos, a aprendizagem ocorre em dois passos: percepção e apreciação. A percepção da diversidade pode tornar-se fator desestabilizador; junto com a apreciação dessa diversidade percebida, induz uma meta-aprendizagem, que demanda o nível cognitivo e o emocional do indivíduo, fazendo-o refletir. Nesse sentido, Cortese (2005, p. 102) esclarece:

Aprender com esses dois passos envolve um importante meta-aprendizado pelo qual o individuo entende que 'o outro é diferente de mim porque eu sou diferente dele', ou seja, o individuo consegue dar um passo atrás e observar a si mesmo pelo olhar do outro.

Desse modo, o encontro com a diversidade fornece aos envolvidos estímulo para reflexão e o processo de aprendizagem que emerge do processo de ensino, revela sua natureza intrinsecamente social, possibilitada pela busca de uma relação autenticamente simétrica entre alunos e professores, na qual todos se tornam capazes de contribuir para um objetivo comum. Nesse processo de ensinar também se reconhece a própria ignorância e o individuo se abre à possibilidade de aprender (Cortese, 2005). 
Com base nas 33 histórias de ensino de 22 gerentes que ensinavam funcionários no trabalho, esse autor identificou e detalhou três processos principais que facilitam aprendizagem na prática de ensinar: observação, escuta e experimentação. Pelo processo de observação, o professor observa o aluno, é por ele observado, e observa a si mesmo. No processo de escuta, o professor presta atenção ao aluno, e no processo de experimentação o professor tenta uma forma diferente de fazer seu trabalho de ensinar.

A pesquisa de Cortese (2005) lhe permitiu afirmar que se aprende pela prática de ensinar num processo de: encontrar-se com a diversidade, refletir, controlar as próprias emoções, e deparar-se com a própria ignorância. Cortese elaborou recomendações para ativar a aprendizagem por meio desta prática, tais como: valorizar os recursos internos de professores e alunos; dialogar, construir oportunidades de treinamento e de aplicação prática específica, trabalhar em pequenos grupos, compartilhar histórias de aprendizagem.

Por fim, o autor diferencia aprender pelo ensinar, da aprendizagem pela vivência (experiential learning), e da aprendizagem pelo erro. No aprender pelo ensinar, o aluno intervém. Nessa intervenção do aluno na relação ensino-aprendizagem, o professor pode perceber-se em sua forma de ser e de agir, ativando os três mencionados processos: observação, escuta e experimentação, em sua prática do ensino. Aprender pelo ensinar permite, assim, focar não só nos resultados e nas ações que não se realizaram, mas nas ações que se tornaram automáticas e escapam ao controle consciente do professor. Permite a reflexão.

\section{Reflexão e aprendizagem}

Reflexão significa, de acordo com Alvesson e Sköldberg (2001, p. vi), "interpretar nossas próprias interpretações, atentando para nossas perspectivas a partir de outras perspectivas e voltando um olhar autocrítico sobre nossa própria autoridade como intérpretes e autores". Por sua vez, a reflexividade na pesquisa qualitativa envolve segundo estes autores:

prestar muita atenção a como o pesquisador pensa sobre seu próprio processo de pensar, a relação entre conhecimento e as formas de fazer conhecimento e a como os diferentes tipos de elementos linguísticos, sociais, políticos e teóricos se entrelaçam no processo de desenvolver conhecimento no qual o material empírico é construído, interpretado e escrito (Alvesson \& Skölberg, 2001, p. 5).

De acordo com Reynolds (1997), deparar-se com a diversidade, tanto interpessoal quanto cultural, ao longo das atividades de ensino, também fornece às pessoas envolvidas estímulos para sua reflexão. Ao refletir atribui-se sentido à informação - sobre si, os outros e o mundo, que emerge no decorrer de sua experiência. Sem essa reflexão, a informação não seria integrada às representações e padrões construídos pelos próprios indivíduos nem provocaria alterações nas formas de pensar e agir.

A reflexão provocada durante o processo de ensinar pode ser de dois tipos: a reflexão na ação definida por Schön (1983), e a reflexão sobre a ação definida por Williamson (1997). Enquanto a primeira se refere a uma forma de conversação com as ações do próprio indivíduo durante o processo de agir, a reflexão sobre a ação significa o estudo das próprias ações depois de finalizadas, o que envolve uma avaliação não apenas dos resultados alcançados, mas também dos meios pelos quais foram alcançados (Cortese, 2005). O potencial para o professor refletir individualmente se desenvolve pelo contato direto com o aluno, porque, de acordo com esse autor, ensinar: (a) suspende a ação do professor e o faz mudar sua atenção do fazer para o pensar, e do pensar para o comunicar; (b) ensinar fornece oportunidade de exposição a problemas não programáveis que leva o professor a criar estratégias para atender especificidades no momento; (c) ensinar é por natureza uma prática social; não apenas envolve a prática do pensar individual, mas também o processo de diálogo e discussão; e (d) ensinar propicia redefinir relações de poder pela possibilidade de perguntar, contra-argumentar e conhecer o pensamento do outro. Assim, ensinar proporciona aprendizagem por fornecer subsídios para o refletir sobre a ação. 
Refletir, de acordo com Raelin (2001, p. 11) significa:

a prática de periodicamente dar um passo atrás para ponderar o significado das ações recentes, para si e para outros do mesmo ambiente. Ilumina a experiência e fornece base para futura ação. Constitui a habilidade de descobrir e explicitar para si e os colegas o que foi planejado, observado ou alcançado na prática. Especificamente, [refletir] privilegia a investigação para alcançar um entendimento de experiências que podem não ter sido detectadas na prática. As experiências se compõem de ações, crenças e sentimentos.

A reflexão, quando feita individualmente (private reflection), apresenta menor poder de mudança que a reflexão pública (public reflection). Na reflexão individual, corre-se o risco de ignorar o que aconteceu, para distanciar-se das emoções negativas no processo de ensinar. Como no processo de reflexão as emoções vivenciadas influenciam; se desconsideradas, podem ampliar ou distorcer os fatos e contribuir ou não para a aprendizagem. A reflexão individual permite afastamento para acalmar-se e, pelo diálogo, retomar a prática. Já a reflexão pública apresenta a vantagem de permitir o reconhecimento das próprias emoções nos outros, iniciar um processo de apoio mútuo e, assim, poder focar a atenção na vivência concreta. Com ela, se podem examinar os dados que emergiram da ação objeto da reflexão e replanejar a própria ação efetivamente observada e vivenciada (Raelin, 2001).

De acordo com o objeto focado, Raelin (2001) distingue três formas de reflexão: (a) a reflexão do conteúdo, segundo a qual se revisa a forma como se aplicaram as ideias ao resolver problemas; (b) a reflexão do processo, pela qual se examina como foi resolvido o problema; e (c) a reflexão da premissa, que vai ao cerne do problema, examinando as próprias questões apresentadas, desafiando as crenças subjacentes ao problema em si.

Esta última forma de reflexão também é chamada autoconsciência teórica e seu resultado é chamado "aprendizagem transformadora" (Raelin, 2001, p. 12). Continuar a refletir requer desenvolver diálogo que pressupõe relações simétricas entre os participantes. Estas de acordo com esse autor podem ser desenvolvidas nos processos de aprendizagem experiencial.

\section{Aprendizagem experiencial ou vivencial}

A aprendizagem experiencial ou vivencial questiona os pressupostos de autoridade no processo de aprender, contestando a ortodoxia. Tornou-se um movimento engajado nos processos políticos da educação e na explanação de processos mentais dos aprendizes. No entanto tem sido mais usada no desenvolvimento de gerentes do que no ensino universitário (Reynolds, 2009). A aprendizagem experiencial oferece possibilidades de aprender pela construção de sentido (sensemaking), ou pelo exame da experiência presente em atividades que são desenhadas pelos professores para esse propósito. Embora Kolb $(1981,1984)$ tenha elaborado este conceito de uma perspectiva cognitivista e individual, os benefícios da aprendizagem experiencial provêm de sua conexão com aspectos sociais e políticos do trabalho e com dilemas e problemas que formam a experiência de trabalho (Reynolds, 2009).

Holman, Pavlica e Thorpe (1997) examinaram, em perspectiva socioconstrutivista, a teoria de aprendizagem experiencial elaborada por Kolb (1984), concluindo que esta se situa na tradição da psicologia cognitiva e, por este motivo, desconsidera ou explica mecanicamente os aspectos sociais, históricos e culturais do self, do pensamento e da ação; por isso propõem uma reconceitualização da aprendizagem experiencial, destacando que o professor deve selecionar e desenvolver o conjunto de habilidades de aprendizagem apropriadas a cada situação, assim como as habilidades para completar cada estágio do ciclo de aprendizagem. Assim, explicitam-se as dimensões estruturais implícitas no processo de aprendizagem experiencial, associando-as às formas de aprender, como se apresenta na Figura 1. 


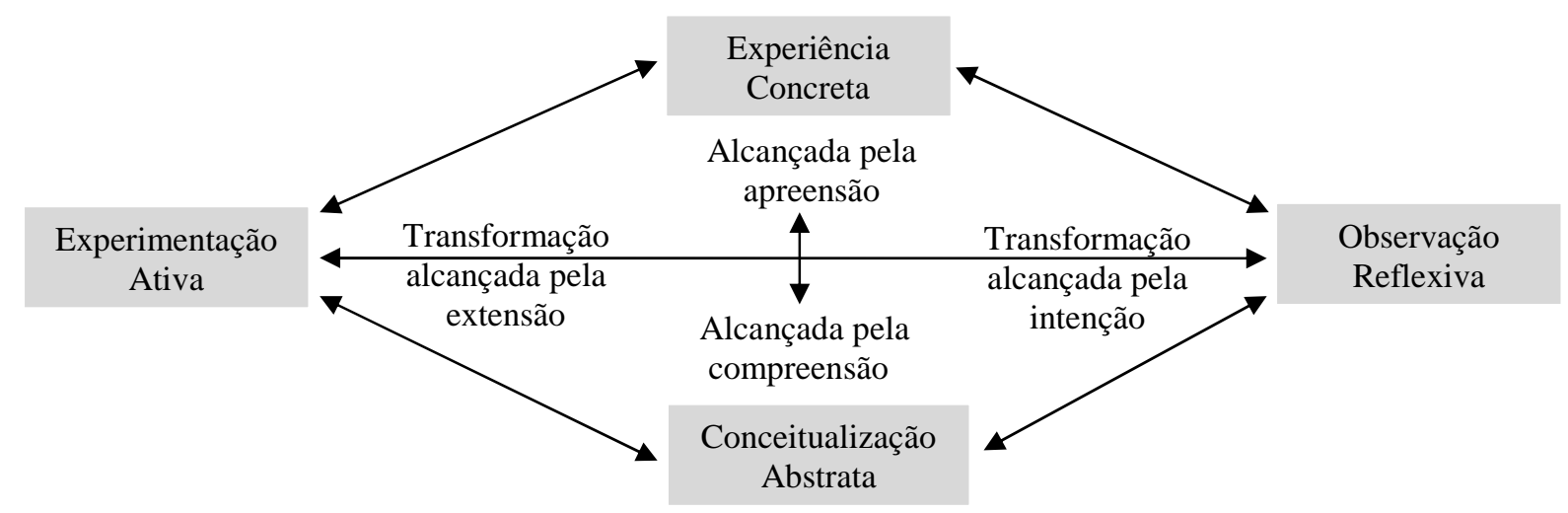

Figura 1. Dimensões Estruturais Implícitas no Processo de Aprendizagem Experiencial.

Fonte: Holman, D., Pavlica, K., \& Thorpe, R. (1997). Rethinking Kolb's experiential learning in management education: the contribution do socio constructivism and activity theory (p. 137). Management Learning, 28(2), 135-148. doi: $10.1177 / 1350507697282003$

O estágio da experiência concreta assume duplo significado: ocorre fora, mas também é o processo pelo qual o indivíduo a percebe. A estrutura de processamento da experiência concreta é a apreensão pela qual o indivíduo percebe os sentimentos em relação a ele. O estágio de observação reflexiva reúne e organiza a informação pelo processo de intenção de aprender, que transforma a experiência. Na conceitualização abstrata se ordena e se constroem modelos e esquemas por meio da compreensão. A experimentação ativa está associada ao agir e fazer no mundo exterior e se distingue da observação reflexiva, porque seu processo transformador implícito é a ação ampliada que segue a experiência apreendida. Dessa forma, para um individuo perceber a experiência concreta e conceitualizá-la de forma abstrata precisa das habilidades de apreender e compreender. É este o escopo da pesquisa qualitativa.

\section{Pesquisa Qualitativa em Administração}

A pesquisa qualitativa, assim entendida aquela que não se vale de estatística ou outros métodos quantitativos, parece estar ganhando espaço e contribuindo para o acervo do conhecimento em administração. Entretanto autores como Cassell, Bishop, Symon, Johnson e Buering (2009) consideram que, entre os numerosos textos que fornecem orientação prática sobre o uso de métodos qualitativos, poucos examinam as habilidades e os processos que facilitam o desenvolvimento de gerentes e pesquisadores organizacionais, bem como o conhecimento necessário à produção de pesquisa qualitativa de qualidade. Com a intenção de sanar essa carência, Cassell et al. (2009), em perspectiva interpretativista, levantaram a percepção de 45 pesquisadores qualitativos do norte europeu, participantes de um projeto em andamento, e descreveram processos de aprendizagem e práticas associadas ao desenvolvimento das habilidades de pesquisa. Concluíram que o processo de tornar-se um pesquisador qualitativo eficaz envolve aprender as habilidades e adquirir conhecimento, por meio de três tipos de prática de pesquisa: reflexão, reflexividade e phronesis, a prática na ação.

De modo geral, a formação para pesquisar cientificamente tem sido considerada como campo de conhecimento a ser adquirido como qualquer outro campo. Aos iniciantes se oferece ensino sobre as técnicas para realizar pesquisa qualitativa e quantitativa, apontando-se as vantagens das diferentes abordagens, metodológicas. Em alguns casos, são expostos ao contexto filosófico que fundamenta essas abordagens, para que possam questionar suas próprias crenças filosóficas (Johnson \& Duberley, 2003). Quando esse questionamento ocorre, de acordo com Jones (1995) geralmente entre doutorandos, a complexidade e a necessária consistência epistemológica e metodológica para elaborar a questão de pesquisa identificar-lhe a natureza e fazer escolhas teóricas e metodológicas pertinentes é percebida. As dificuldades para realizar sua pesquisa sobre comportamento humano e organizacional foram relatadas por esse autor, que convida os iniciantes na pesquisa a assumir uma prática reflexiva, 
para refletir no processo de teorizar e aprender a justificar as próprias escolhas dos métodos. Sugere examinar seus fundamentos epistemológicos que conformam paradigmas.

\section{Paradigmas de pesquisa e do pesquisador}

A epistemologia positivista considera que o conhecimento se constrói pelo uso do método cientifico. Por seu turno, os pesquisadores qualitativos enfatizam que a importância e a legitimidade da interpretação dos eventos - subjetivos por natureza - é concedida pelos agentes, não apenas pelo método, por isso os dados originados de pesquisa quantitativa têm sido denominados na academia, hard, objetivos rigorosos e confiáveis, enquanto os originados de pesquisa qualitativa seriam soft, e subjetivos por natureza (Jones, 1995).

Burrel e Morgan (1979) esclarecem que o nominalismo admite a subjetividade envolvida no processo de produção de conhecimento, reconhece que a realidade a ser estudada é produto da consciência do indivíduo e a subjetividade é integrante do conhecimento do indivíduo; portanto é também do pesquisador. De acordo com o subjetivismo, o indivíduo percebe a realidade, incluindo a si mesmo, ser humano gerador de processos sociais por meio de relações intersubjetivas, que considera capazes de construir na sua relação com a realidade. Nessa direção se encontra o interpretativismo, que assume a realidade final de estar no espírito, na ideia, e não apenas no que é percebido pelos sentidos. Sua busca é por conhecer como a realidade social é construída e perceber as relações simbólicas que permeiam a vida organizacional. O interpretativismo defende que o objetivo das ciências humanas é compreender a ação humana (Schwandt, 2000). Muitas são as abordagens denominadas interpretativistas, mas todas têm em comum partir da interpretação humana como foco de análise com a preocupação de compreender como a realidade é socialmente construída, o processo pelo qual o individuo, utilizando sua subjetividade, apreende uma observação ou vivência, a examina, e lhe dá sentido, ou seja, a interpreta. Observações e vivências geram o comportamento do indivíduo, que provém de uma ação por ele gerada, para alcançar o que deseja, de acordo com sua interpretação subjetiva do significado do resultado dessa ação. Para interpretar a ação do indivíduo parece, pois, que o pesquisador qualitativo vivencia, apreende, explica e compreende (Burrel \& Morgan, 1979). A compreensão, de acordo com Edgar Morin (1999, p. 158), se realiza a partir da explicação. Compreender significa "modo fundamental de conhecimento para qualquer situação humana implicando subjetividade e afetividade ... para todos os atos, sentimentos, pensamentos de um ser percebido como indivíduo-sujeito". A compreensão se distingue da explicação por sua conotação sintética e por ser um conhecimento empático das atitudes, sentimentos e intenções dos outros. Pela explicação se concebe a finalidade a partir dos objetos; e pela compreensão a finalidade é alcançada a partir dos sujeitos. Sendo assim, enquanto a compreensão dos fenômenos inclui o sujeito, a explicação o exclui. Estas situações terão de ser aprendidas pelo pesquisador (Morin, 1999).

\section{Pesquisa como uma forma de aprender}

As características da pesquisa organizacional, numa perspectiva da aprendizagem gerencial, foram investigadas por Vince (1995). Para tal ele parte da ideia de pesquisa como aprendizagem e integra as dinâmicas dos processos de pesquisar e de aprender. Assim, esse autor gera um arcabouço de análise formado por quatro princípios gerais, associados a quatro conceitos-chave para compreender pesquisa como aprendizagem. Os princípios gerais são: (a) pesquisa é processo de desenvolvimento que envolve pesquisador e pesquisado na possibilidade de mudança - aprendizagem; (b) pesquisa é processo pessoal motivado pelo desejo de ampliar o próprio conhecimento e entendimento; (c) pesquisa é vivencial, tendo a experiência vivida por ambos, pesquisador e pesquisado, valor e impacto; (d) pesquisa é processo reflexivo, porque reconhece a relação contínua entre a teoria e a prática, ao mesmo tempo que cria e molda o conhecimento, comportamento, estrutura e sistemas individuais e organizacionais (Vince, 1995). Desse modo, o processo de pesquisa é, de acordo com o autor, um processo autorreflexivo que se define associado a quatro conceitos-chave: vinculação, emoção, poder e dinâmicas inconscientes, que conectam a aprendizagem à pesquisa pelo engajamento do pesquisador. Tal compromisso provoca ansiedade, nem sempre controlável ou 
consciente, que em interação com a estrutura gera um processo dinâmico, no qual o indivíduo e a organização se moldam e limitam o individuo e a organização.

Percebe-se, pois, que aprendizagem e pesquisa não estão separados da emoção humana nem das relações de poder que impactam essa interação humana e sua gestão. Assim sendo, pela reflexão permanente, o pesquisador gera sempre mais questionamentos, ao examinar os princípios e processos da própria pesquisa como forma de aprendizagem.

\section{A aprendizagem do pesquisador sobre sua forma de pesquisar}

No âmbito da prática da administração, os pesquisadores que acreditam estar engajados somente na atividade técnica de ajudar os gerentes, desconsideram o simbólico nas ciências humano-sociais. Neste sentido, não concebem o "mundo da prática gerencial como rede de significados subjetivos, onde os gerentes precisam interpretar o significado de suas próprias ações, assim como a dos outros, e atribuir-lhes significado e sentido" (Astley, 1984, p. 269). Parece então que construir conhecimento pela pesquisa é um processo social, não apenas individual, como defende Romm (2002), alertando que entender a aprendizagem como processo social complexo - não só individual e cognitivo - e a mudança como implícita nos processos de aprendizagem, requer novas perspectivas diferentes daquelas do positivismo, tais como a proposta pelo construtivismo social. O construtivismo social admite a subjetividade, a natureza social e a necessária interdependência e compartilhamento de conhecimento nos grupos, para que a produção de conhecimento e uma mudança pela aprendizagem aconteçam. Essa indissociabilidade das dimensões objetivas e subjetivas é reconhecida na pesquisa qualitativa que utiliza, geralmente, a entrevista como seu método de interação com o campo de pesquisa em busca de dados e informações.

\section{A Entrevista como Método de Coleta de Dados no Campo}

Vergara (2009) definiu entrevista, apontou sua utilidade e tipos. Destacou as possibilidades e suas limitações, assim como os cuidados para conduzir uma entrevista. Recomenda, por fim, que a entrevista seja planejada, executada e interpretada para contribuir com informações consistentes com a pesquisa de administração.

\section{Conceito e procedimentos para entrevistar}

Entrevista, de acordo com Vergara (2009), é uma interação verbal que enseja troca de significados do entrevistador com o entrevistado, que estabelece, no tempo da entrevista, um relacionamento de modo a se produzir conhecimento sobre algo. Sua finalidade é obter dados e informações, é interagir com o campo. Utiliza-se entrevista, quando se quer obter informações de dentro do indivíduo, relativas à experiência vivida. Para tal, o entrevistador deverá preparar-se para captar, durante o momento da entrevista, o dito e o não dito, os significados, sentimentos, reações, gestos, tom e ritmo de voz, elementos da subjetividade do individuo. A escolha da estrutura da entrevista, se fechada, semiaberta ou aberta depende do problema de investigação.

Por se tratar de um momento de encontro, o tempo para relacionamento e a qualidade que o entrevistador desenvolve na entrevista determinarão a riqueza dos depoimentos; por isso e por tratar-se de uma situação social complexa, entrevistar demanda do entrevistador preparação especifica que minimize uma posição defensiva do entrevistado. O entrevistador deve organizar suas ideias, estruturando-as num roteiro de entrevista que lhe servirá de guia, de modo a focar a posição do entrevistado e, assim, trazer dados que ajudem a responder ao problema de pesquisa. Para construir esse roteiro, o entrevistador apoia-se no referencial teórico que fundamenta o estudo, em informações da prática de pessoas das organizações, ou ainda, em conclusões da vivência própria e de outros. A elaboração de roteiro, sua validação semântica e de conteúdo, por meio de entrevista piloto, é 
recomendada para melhor preparo do entrevistador e aproveitamento de seus resultados, assim como a atenção às limitações e possibilidades da entrevista como método de coleta de dados e informações no campo. As limitações atribuíveis à capacidade interpretativa do entrevistador para estabelecer empatia com seu entrevistado podem ser superadas por meio de ensaio numa entrevista-piloto (Vergara, 2009).

Os cuidados relativos à realização da entrevista, ainda segundo esta autora, dizem respeito, entre outros, à escolha do entrevistado, à forma de realizar os contatos prévios, durante e no fim da entrevista, a não ser tendencioso e buscar estabelecer uma relação de confiança com o entrevistado. Inclui reconhecer os preconceitos do entrevistador, registro minucioso do procedimento e das reações, tanto do entrevistador quanto do entrevistado, para compartilhar com o leitor e, assim, permitir compreender melhor os resultados do campo que comporão o relatório da investigação. Por fim, o procedimento para realizar a entrevista individual considera três momentos: (a) Planejamento, que se inicia pela indagação do pesquisador que perguntas devo fazer a meu entrevistado para dar resposta a meu problema de pesquisa; envolve submeter o roteiro proposto a juízes, atenção à formulação das questões criadas, e realização de entrevistas-piloto, considerando a possibilidade de gravação. (b) Execução, que demanda capacidade do entrevistador em estabelecer rapport com o entrevistado, com tranquilidade, elegância, gentileza, simpatia, empatia, encorajamento e adição de perguntas esclarecedoras. Nesse sentido, Vergara (2009, p. 28) sinaliza: "um bom rapport é meio caminho andado para que o entrevistado, sentindo-se mais à vontade, apresente menos racionalização normativa e opiniões superficiais". Assim, desenvolver rapport e plena atenção às respostas do entrevistado é central para o entrevistador alcançar melhor compreensão das palavras do entrevistado. (c) Conclusão, quando o entrevistador agradece, registra em seu caderno de campo suas impressões da entrevista, transcreve, e procede ao tratamento das informações coletadas e à interpretação do depoimento.

\section{Refletindo sobre a entrevista como método de coleta de dados na pesquisa qualitativa}

Alvesson (2003) realiza um exame da entrevista como método de pesquisa, identificando e reconceitualizando as perspectivas predominantes no campo. Assim, estimula a reflexão sobre o uso do material das entrevistas e aponta implicações metodológicas para praticar a pesquisa.

A entrevista qualitativa é um modo de produção de conhecimento diferente dos questionários falados. Entrevistas são relativamente estruturadas e abertas ao que o entrevistador considerar importante falar, dentro do foco de pesquisa. Seus defensores a consideram um rico registro da experiência, conhecimento, ideias e impressões dos entrevistados que podem ser documentadas. Entretanto considerar a entrevista como forma de sabatinar o entrevistado sobre sua experiência ou práticas sociais, negligencia a entrevista como situação social e linguisticamente complexa. Por isso é importante não simplificar nem idealizar a situação de entrevista, assumindo que, desde que se sigam técnicas de entrevista corretas, o entrevistado se tornará um interlocutor competente e relatará a verdade a serviço da ciência, produzindo dados que revelam seu interior ou fatos da organização. Adicionalmente, a complexidade social e linguística deve ser considerada e não apenas como fonte de tendenciosidade. Maior entendimento teórico, ou seja, uma perspectiva reflexiva que considere os vários pontos de vista teóricos relativos à entrevista se faz necessário. Sem esse entendimento corre-se o risco de usar ingenuamente o material resultante da entrevista, e realizar interpretações em terreno inconsistente (Alvesson, 2003).

$\mathrm{O}$ autor destaca três vertentes epistemológicas que informam o conceito de entrevista para pesquisa e, assim, as classifica, denominando-as entrevista neopositivista, romântica e localista. A entrevista neopositivista imita os ideais quantitativos, buscando dados numa realidade fora do pesquisador, por meio de protocolos que pretendem minimizar a influência do pesquisador e a tendenciosidade. Assim, produzem, analisam e codificam grandes quantidades de dados, preocupados em dar máxima transparência a um processo de pesquisa objetivo e neutro. O problema destes pressupostos é que os respondentes podem produzir respostas superficiais e cautelosas. Para superar problemas de confiança e controle percebidos, os pesquisadores entrevistam mais de uma vez, buscam consistência no tempo entre as entrevistas ou concedem mais tempo para os entrevistados refletirem 
sobre seus depoimentos. De outro lado, a entrevista romântica é produzida por pesquisadores que defendem interações humanas mais genuínas, acreditam em estabelecer rapport, confiança e compromisso entre o entrevistador e o entrevistado, especialmente no momento de entrevista, como requisito para explorar o mundo interior dos significados, ideias, sentimentos, intenções ou a realidade social vivenciada pelo entrevistado. A meta deste tipo de entrevista é alcançar conceptualização mais profunda e plena dos aspectos das vidas dos sujeitos. Envolvimento ou emissão de opiniões pessoais devem ser evitados e buscar engajar-se numa real conversação com entendimento empático é o papel deste pesquisador. Essas medidas tornam as entrevistas mais honestas, moralmente corretas e confiáveis, porque o respondente, ao ser tratado como igual, expressa seu sentimentos pessoais e apresenta um retrato mais real do que pelos métodos tradicionais de entrevista. Já a entrevista localista produz-se enfatizando que os depoimentos da entrevista devem ser considerados em seu contexto social. Defendem seus adeptos que nas entrevistas as pessoas não estão relatando eventos externos, mas produzindo suas histórias com seus recursos culturais; nesse sentido, a entrevista é um evento socialmente produzido a ser examinado como tal. Por isso pesquisadores localistas, cautelosamente, afirmam o entrevistado relatou seu sentimento de dor, e consideram suas interpretações apenas uma interpretação provisória. Embora a entrevista seja reconhecida pelos localistas como fonte válida de produção de conhecimento, as condições locais e sociais devem ser consideradas para alcançar resultados válidos (Alvesson, 2003).

Por fim, continuando a refletir, o autor desenvolve conceitualmente a ideia de entrevistar por meio de metáforas para entender-lhe o significado, tanto do momento quanto dos depoimentos obtidos da entrevista. Propõe usar metáforas como forma de prestar maior atenção à abstração teórica e ao uso de linguagem, estimulando, assim, uma abertura do pesquisador para identificar padrões complexos e superar a visão da entrevista como método de pesquisa que apenas requer otimização de técnicas e minimização da tendenciosidade (bias). Alvesson (2003, p. 14) conclui o seguinte.

Uma atitude reflexiva na pesquisa traz duas vantagens: evitar a ingenuidade associada à crença que os 'dados' simplesmente revelam a realidade e, gerar o reconhecimento da riqueza de significados originados do material empírico complexo. A reflexividade [na pesquisa] é praticada em ambientes onde se estimule um diálogo nos qual se produzem interpretações que são, a seguir, desafiadas. Inclui abertura para explorar significados reconhecendo a ambigüidade no fenômeno e as linhas de pesquisa favorecidas. Isso significa construir uma ponte entre as preocupações epistemológicas e o método.

Conectar a epistemologia às teorias e métodos é uma forma de refletir em outro nível, que se realiza abstraindo, dos dados do campo, conceitos à luz dos aportes teóricos já desenvolvidos.

\section{Entrevistando no Campo e sobre Ele Refletindo}

Para ilustrar a aprendizagem da pesquisa qualitativa, um episódio é apresentado neste artigo: a experiência de realização de entrevista piloto no campo. O foco na reflexão no e sobre o campo foi dado para acompanhar o processo de aprendizagem de mão dupla, ocorrido na aprendizagem experiencial proposta.

\section{Refletindo no campo}

A aprendizagem pela experiência aqui narrada ocorreu durante a participação dos quatro mestrandos calouros que continuam no projeto de pesquisa interinstitucional que está em andamento. Os mestrandos, dois homens e duas mulheres, na faixa etária de 28 a 32 anos, são três bacharéis de administração, um deles também bacharel de filosofia, e um bacharel de matemática. Profissionalmente três deles atuam como servidores públicos federais em áreas de recursos humanos de suas respectivas organizações, e um deles como professor na graduação, havendo também coordenado um curso de graduação. 
Desde o início de julho de 2009, nós, professoras, estabelecemos com os alunos encontros regulares, abrimos grupo virtual para discussões pela internet e estabelecemos atividades presenciais específicas para cada fase de pesquisa. Para a primeira revisão de literatura, que foi feita por palavrachave, os alunos elaboraram quadros síntese de leitura para serem apresentados ao grupo. Para a pesquisa de campo, discutiram-se os elementos do roteiro. Para a preparação de entrevista exploratória por meio de roteiro, foram realizadas discussão e preparação de cada aluno para ser um entrevistador; também foi pedido que fizessem anotações logo após a entrevista. Já haviam sido pedidos diários de campo, nos quais registrariam por escrito seu aprendizado com cada tarefa e evento do projeto. Feitas as duas primeiras atividades, foram compartilhadas pela internet, apresentadas em reuniões especificas extraclasse; por exemplo, em oficinas, nas quais cada um se manifestava, indicando suas dificuldades e avanços. Por ter sido vivenciada de forma mais intensa, oferecendo riqueza de elementos para a reflexão pública dos quatro mestrandos, será detalhada a experiência de um deles: Américo. Ela revelou sete passos da experiência individual: preparação, realização, transcrição e reflexão sobre o conteúdo do transcrito, preparação do relato da experiência de entrevistar, leitura de um livro sobre o processo de entrevistar, elaboração de uma apresentação oral, elaboração de novo relatório individual privilegiando o aprendizado alcançado. A experiência de Américo também revelou quatro passos de reflexão publica sobre a aprendizagem: comparação das experiências vividas, questionamentos, expressão de sentimentos e conclusões.

A preparação para entrevistar foi feita individualmente, sem leitura prévia do aluno sobre como conduzir uma entrevista. Foram pelo menos três encontros e em cada um dos quais uma de nós, professora, indicava ao aluno o que se esperava de um entrevistador, levantando com ele as dúvidas, pensando junto com ele as possíveis respostas que o entrevistador poderia dar, assim como os cuidados na seleção dos sujeitos para a entrevista piloto, alertando-o para não influenciar as respostas. Em suma, o aluno foi orientado a ouvir mais que falar.

Depois da realização de três entrevistas piloto, segundo passo da experiência, elas foram por ele transcritas, configurando-se como terceiro passo e seu conteúdo provocou reflexão. Nessa tarefa o aluno identificou como havia seguido as perguntas do roteiro, aquelas que não havia feito, as que havia improvisado, e as respostas que havia provocado no entrevistado. Preparando o relato dessa experiência de entrevistar, individualmente, o aluno foi surpreendido ao perceber que ao invés de ouvir, havia interrompido e qualificado os depoimentos com o entrevistado. Isto gerou desconforto e frustração; mas, depois que uma de nós apontou como fazer e assegurou que é um processo complexo mesmo, o aluno reconheceu: "Fiquei frustrado porque X falou tão pouco!" ou, "Já conhecia X, por isso sabia a que se referia e comentei [junto com ele] também ... [sem perceber que desse modo estava interrompendo meu entrevistado]'.

Uma vez feitas as entrevistas (presenciais), foi indicado ao Américo um livro sobre como fazer entrevista, cuja leitura the fez deduzir: "Fiz tudo errado!", revelando a tensão emocional que o processo de aprender a entrevistar provocava, ao se ver (se reconhecer) nas transcrições e comparar seu comportamento com o recomendado no livro para realizar entrevistas no campo.

Foi então pedido ao aluno que elaborasse uma apresentação num encontro extraclasse (oficina), quando daria seu depoimento sobre a experiência de entrevistar, disponibilizando o próprio arquivo da gravação e destacando os pontos do roteiro e de sua atuação como entrevistador, e o que mudaria, se fosse entrevistar de novo. O próprio processo de elaborar a apresentação ia fazendo o aluno refletir de modo que, na apresentação pública, pôde dar exemplos específicos de cada passo do processo, assim como ouvir dos colegas questões que atiçavam mais sua reflexão: considerarias ético pagar para o entrevistado pelo tempo que ele dá à entrevista? foi uma indagação que o fez questionar-se e responder a seguir: "assim você teria grande risco de ouvir o que for politicamente correto ou o que o entrevistador achar que você quer ouvir". Sobre o tempo que uma transcrição demanda, foi questionado pela platéia: [se a transcrição de entrevistas demora, e é tão trabalhosa], não seria melhor mandar um profissional transcrever?' Essa opção o aluno reconheceu possível, mas ponderou que quando não se faz pessoalmente a transcrição perdem-se detalhes importantes para fazer a interpretação: "somente quem esteve com o entrevistado pode observar seus gestos, paradas, ironias...", reconheceu. 
Após essa apresentação pública foi pedido novo relatório individual, mais especifico, para que o aluno expressasse o que aprendeu e como essa experiência de entrevistar impactou na elaboração do roteiro e de seu próprio projeto de pesquisa. Em relação ao roteiro, Américo afirmou: "Revisei algumas perguntas que eram muito diretas, ou seja, que levariam o entrevistado a responder sim ou não apenas. A revisão me ajudou a perceber como o entrevistador pode contaminar a entrevista ao emitir opiniões próprias ou completar respostas do entrevistado". E, em relação a seu projeto de dissertação, disse: "Além de revisar as perguntas do roteiro, conforme citado na questão anterior, procurei verificar se as perguntas que fiz atendiam aos meus objetivos da pesquisa". Adicionalmente, levando seu aprendizado para outras disciplinas, Américo manifestou: "na disciplina [outra disciplina] construí um roteiro, sem saber ao certo como iria fazer a análise; este erro já não cometi, quando elaborei o roteiro do meu projeto de pesquisa. A Oficina1 ajudou a perceber quão grande estava minha amostra, me fez refletir que para fazer entrevistas de qualidade precisava reduzir o número de entrevistados".

Em relação aos sentimentos que vivenciara na entrevista, Américo disse:

"Confirmei [ao entrevistar] que falo demais, que é necessário estar atento ao planejamento... Me senti um pouco perturbado, pois falei muito; assim havia uma efervescência interna, causando ruído na atenção à entrevista. Estava inseguro, pois imaginava que a entrevista durasse mais tempo".

O depoimento do Américo, o qual incluía a gravação da entrevista foi ouvido pelos alunos. Uma aluna do mestrado assim se expressou:

"meu roteiro ainda não estava elaborado [mas] ajudou tanto quando ouvi as entrevistas que Américo fez ... quanto ao ouvir o depoimento do Américo essa dificuldade que temos em manter certo afastamento durante a entrevista. [percebi que] temos uma tendência a conversar com o entrevistado; mas, na verdade, a entrevista não é um bate-papo, não estamos buscando uma troca de opiniões e sim as respostas dos entrevistados; para isso é necessário não interferir. No entanto isso é difícil, porque gostamos do assunto e temos vontade de falar sobre ele [ao entrevistado]". (Ofélia).

Por fim, ao ser perguntado sobre o aprendizado que a vivência trouxe, Américo respondeu: "Sinto-me mais seguro para realizar uma entrevista". E os outros mestrandos, que também estavam realizando entrevistas para seus respectivos projetos e assistiram Américo, revelaram suas conclusões sobre a experiência que todos viveram:

"Senti muito prazer com o processo de entrevistar, de ouvir o entrevistado, de ler a transcrição. Consegui perceber como as entrevistas enriquecem uma pesquisa e também como a subjetividade está presente em pesquisas na área de gestão, principalmente que meu foco é gestão de pessoas. Para minha formação de Mestre não poderia faltar este aprendizado. Um mestrado na área de gestão precisa formar Mestres, futuros gestores, que saibam ouvir, que saibam lidar com a subjetividade e entender a complexidade dos ambientes e das pessoas" (Solange).

“O aprendizado me proporcionou uma reflexão sobre o processo científico como um todo. Foi possível constatar que o simples fato de parar e ouvir o outro pode proporcionar a descoberta de questões cruciais para a organização. Vislumbrei também que a realização das entrevistas pode ser um momento de desabafo sobre suas insatisfações com a organização e que revela, de alguma forma, a necessidade de intervenção da gestão para [procurar] solucionar" (Marcelo).

"Estou me sentindo mais confiante, mais preparada. Sempre que não temos experiência em algo nos sentimos despreparados, vulneráveis e esta oficina ajuda a tirar as dúvidas, mostrar os possíveis erros que vamos cometer e, aprender com a experiência dos outros. As entrevistas são muito importantes na formação de mestre por permitir que o pesquisador investigue as percepções das pessoas. Trabalho na área de Gestão de Pessoas e por isso acho que para mim isso é ainda mais importante, porque é uma área em que a abordagem qualitativa é essencial para compreender a subjetividade das pessoas” (Ofélia).

Os primeiros resultados empíricos desta experiência sugerem que os alunos aprenderam a pesquisar, vivenciando a pesquisa que ativou processos de reflexão individual e pública. Assim, se aperceberam de sua própria prática como entrevistadores, apreenderam os pressupostos da pesquisa qualitativa, e com essa consciência deram inicio à construção de conhecimento para seus projetos de 
pesquisa. Nós, docentes destes alunos, por nossa vez, ao refletirmos sobre nossa prática no ensino de pesquisa qualitativa e, com nossos alunos, sobre seus avanços, estabelecemos intersubjetividade, identificamos e criamos oportunidades de aprendizagem, desenvolvendo espaços para estimular-lhes vivência. Assim, mudamos nossa própria prática para incluir um processo de ensino-aprendizagem de mão dupla.

\section{Refletindo sobre o trabalho realizado com os alunos}

Os dados obtidos no campo junto aos alunos, por meio de observações, anotações, discussões e entrevistas formais e informais foram coletados ao longo de um ano, durante as aulas, discussões presenciais e virtuais e oficinas. $\mathrm{O}$ arcabouço teórico, no início deste episódio, foi composto pelas teorias e conceitos que fundamentam a própria prática de ensino e pesquisa das autoras deste artigo, e uma experiência na docência suficiente para perceber as dificuldades apontadas no inicio deste estudo, e reconhecer que cabia a nós fazer modificações em nossos métodos de ensino para manter o entusiasmo dos alunos por aprender. Ao avançar na fundamentação teórica nós, professoras, fomos acompanhando o desdobramento da vivência em dois níveis: os textos sobre a prática de entrevistar e os estudos que a questionavam, examinando suas raízes teóricas. Assim, íamos ganhando mais consciência sobre a consistência e as inconsistências das próprias práticas. Por isso, além de aprofundar nossas leituras para lecionar a disciplina, o fizemos para entender os problemas que nossa prática de ensino de Metodologia da Pesquisa estava trazendo à tona em sala de aula e buscar, ativamente, reativar espaços de aprendizagem inclusivos, isto é, passamos a estudar para explicar e compreender a lógica dos alunos e os sentimentos que o estudo sobre algo novo lhes provocava.

O projeto interinstitucional em andamento foi o ensejo que buscávamos para praticar aprendizagem experiencial, mesmo em se tratando de alunos calouros. A primeira surpresa foi a de que alunos que perceberam o propósito de nós, professoras, como de interesse para eles também, se envolveram e, refletindo, conseguiram trazer questionamentos para trocar dentro e fora da sala de aula evidencia-se, assim, um aprendizado de mão dupla. Por fim, o próprio processo de relatar e sistematizar esta vivência levou a nós, docentes, a rever o ciclo de aprendizagem de Kolb (1984) com mais consciência de cada fase e de cada processo de aprendizagem que as sustentam.

No processo nós, autoras deste estudo, percebemos que, por meio de reflexão, o pesquisador, mesmo iniciante, pode ganhar consciência do seu papel de pesquisador e da natureza da pesquisa que realiza. Examinando os aportes teóricos sobre essa prática, foi possível identificar pelo menos quatro tipos de reflexão: a individual, a pública, a reflexão que se realiza na ação e a que se realiza, a posteriori, denominada reflexão sobre a ação realizada.

Também percebemos que a prática destes tipos de reflexão, no inicio não tão consciente, ajudou a entender os rumos e desdobramentos que a experiência de pesquisar em um projeto de pesquisa real trouxe aos alunos e a nós, suas professoras de Metodologia de Pesquisa.

\section{Conclusões e Implicações do Estudo Realizado para a Formação de Mestres}

O estudo aqui apresentado foi desencadeado a partir do seguinte problema: Como os mestrandos aprendem, por meio da prática experiencial, a realizar pesquisa qualitativa de administração?

Do ponto de vista conceitual, percebemos que os mestrandos praticaram entrevista orientada pelos pressupostos da entrevista do tipo romântico e também da localista, nos termos de Alvesson (2003).

Do ponto de vista da prática docente, os resultados revelaram que a reflexão pública, em sala de aula e durante os eventos específicos extraclasse, ativou a aprendizagem experiencial alcançada pelos participantes. Também revelaram que a prática de reflexão pública no campo e sobre o campo ampliou 
a consciência dos participantes, bem como apontou implicações para o ensino de metodologia de pesquisa, pesquisa qualitativa, orientação de mestrandos e a gestão de IES.

Especificamente, destacamos dois tipos de implicações práticas deste estudo, uma para os docentes e outra para os gestores de IES.

1. Para elaborar a disciplina Metodologia de Pesquisa sob uma perspectiva de ensino-aprendizagem, docentes devem: considerar o ambiente de ensino, intra e extraclasse, como espaços de aprendizagem; construir espaços e oportunidades para aprendizagem experiencial; construir ambientes de diálogo e reflexão pública em que se compartilhem vivências; criar atividades para que os alunos pratiquem suas habilidades para pesquisar acompanhados pelos professores e orientadores e dando-lhes feedback oportuno; criar atividades para estimular reflexão regularmente, tais como relatórios e diários de campo; considerar o tempo necessário à reflexão na realização das atividades de ensino.

2. Para a formulação didático-pedagógica de seus cursos, os gestores de IES devem: considerar que a aprendizagem vivencial é interdisciplinar e complexa por natureza; no processo de aprendizagem é necessário considerar um tempo para reflexão pública dos alunos e tempo para vivenciar, além do tempo para estudar.

No que concerne a questões para futura pesquisa, o estudo levantou duas: (a) como, no Brasil, são percebidos os requisitos necessários para realizar pesquisa qualitativa de qualidade? (b) A prática de reflexão na ação e da reflexão sobre a ação parece necessária à elaboração do relatório de campo e discussão empírico-conceitual esperadas na pesquisa tradicional. Seria esclarecedor examiná-las em seu impacto metodológico para a pesquisa qualitativa. pública.

Compartilhando a experiência refletida, convidamos os leitores deste artigo à prática da reflexão

Artigo recebido em 21.11.2010. Aprovado em 31.05.2011.

\section{Agradecimentos}

O presente trabalho foi realizado com o apoio da CAPES, entidade do Governo Brasileiro voltada para a formação de recursos humanos por meio de seu Programa Pro-Administração, do qual ambas as autoras são beneficiárias.

\section{Referências}

Aktouf, O. (1996). A administração entre a tradição e a renovação. São Paulo: Atlas.

Alvesson, M. (2003). Beyond neopositivists, romantics and localists: a reflexive approach to interviews in organizational research. Academy of Management Review, 28(1), 13-33. doi: $10.2307 / 30040687$

Alvesson, M., \& Sköldberg, K. (2001). Reflexive methodology. New vistas for qualitative research. London, UK: Sage Publications.

Antonello, C. S., \& Godoy, A. S. (2009). Uma agenda brasileira para os estudos em aprendizagem organizacional. Revista de Administração de Empresas, 49(3), 266-281. doi: 10.1590/S003475902009000300003 
Astley, G. W. (1984). Subjectivity, sophistry and symbolism in management science. Journal of Management Studies, 21(3), 259-272. doi: 10.1111/j.1467-6486.1984.tb00410.x

Burrel, G., \& Morgan, G. (1979). Sociological Paradigms and organizational analysis. London: Heinemann.

Cassell, C., Bishop, V., Symon, G., Johnson, P., \& Buering, A. (2009). Learning to be a qualitative management researcher. Management Learning, 40(5), 513-533. doi: $10.1177 / 1350507609340811$

Chanlat, J. F. (1996). Por uma antropologia da condição humana nas organizações. In J. F. Chanlat (Coord.), O individuo na organização. Dimensões esquecidas (Vol. 1, pp. 21-45). São Paulo: Atlas.

Coordenação de Aperfeiçoamento de Pessoal de Nível Superior. (2011). Avaliação trienal 2010. Recuperado em 20 março, 2011, de http://trienal.capes.gov.br/?page_id=100

Cortese, C. G. (2005). Learning through teaching. Management Learning, 36(1), 87-115. doi: $10.1177 / 1350507605049905$

Easterby-Smith, M., \& Araújo, L. (1999). Organizational learning: central debates and opportunities. In M. Easterby-Smith, J. Burgoyne, \& L. Araújo (Eds.), Organizational learning and the learning organization: developments in theory and practice (pp. 1-21). London: Sage Publications.

Fischer, T., Nicolini, A. M., \& Silva, M. R. de (2005). Aos mestres de administração. Revista $O \& S$. 12(35), 109-111.

Freire, P. (1967). Educação como prática da liberdade. Rio de Janeiro: Paz e Terra.

Freire, P. (2000). Pedagogia da autonomia: saberes necessários à prática educativa. São Paulo: Paz e Terra.

Griffiths, D. S., Winstanley, D., \& Gabriel, Y. (2005). Learning shock: the trauma of return to formal learning. Management Learning, 36(3), 275-297. doi: 10.1177/1350507605055347

Hendry, J., \& Seidl, D. (2003). The structure and significance of strategic episodes: social systems theory and the routine practices of strategic change. Journal of Management Studies, 40(1), 175-196. doi: 10.1111/1467-6486.00008

Holman, D., Pavlica, K., \& Thorpe, R. (1997). Rethinking Kolb's experiential learning in management education: the contribution do socio construtivism and activity theory. Management Learning, 28(2), 135-148. doi: 10.1177/1350507697282003

Johnson, P., \& Duberley, J. (2003). Reflexivity in management research. Journal of Management Studies, 40(5), 1279-1303. doi: 10.1111/1467-6486.00380

Jones, O. (1995). No guru, no method, no teacher. A critical view of (my) managerial research. Management Learning, 26(1), 109-127. doi: 10.1177/135050769502600110

Kolb, D. A. (1981). Experiential learning theory and the learning style inventory: a reply to Freedman and Stumpf. The Academy of Management Review, 6(2), 289-296. doi: 10.2307/257885

Kolb, D. A. (1984). Experiential learning: experience as the source of learning and development. New Jersey: Prentice-Hall.

Marques, R. G. (2008). Diagnóstico institucional dos programas de pós-graduação do Estado de Rio de Janeiro. Recuperado em 15 fevereiro, 2011, de http://www.faperj.br/servicos/buscaposgrad/pos_grad_RJ_apresentacao.phtml 
Morgan, G., \& Smircich, L. (1980). The case for qualitative research. The Academy of Management Review, 5(4), 491-500.

Morin, E. (1999). O método 3: o conhecimento do conhecimento. Porto Alegre: Sulina.

Nicolini, A. (2003). Qual será o futuro das fábricas de administradores? Revista de Administração de Empresas, 43(2), 44-54. doi: 10.1590/S0034-75902003000200003

Orpen, C. (1998). The causes and consequences of academic procrastination: a research note. Westminster Studies in Education, 21(1), 73-75. doi: 10.1080/0140672980210107

Parecer CES/CFE n. 977, de 3 de dezembro de 1965. (1965). Definição dos cursos de pós-graduação. Brasília: CAPES. Recuperado em 15 fevereiro, 2011, de http://www.capes.gov.br/images/stories/download/legislacao/Parecer_CESU_977_1965.pdf

Portaria CAPES n. 080, de 16 de dezembro de 1998. (1998). Dispõe sobre o reconhecimento dos mestrados profissionais e dá outras providências. Brasília: CAPES. Recuperado em 15 fevereiro, 2011, de http://www.ufrgs.br/propg/regulam/anexos/port80_98.htm

Portaria Interministerial n. 270, de 22 de maio de 2003. (2003, maio 26). Institui a Comissão Interministerial para o desenvolvimento da pós-graduação e da ciência e tecnologia. Diário Oficial da União (Seção 2, p. 6). Brasilia: MCT/ME.

Raelin, J. (2001). Public reflection as a basis of learning. Management Learning, 32(1), 11-30. doi: $10.1177 / 1350507601321002$

Resolução CNE/CES n. 1, de 3 de abril de 2001. (2001). Estabelece normas para o funcionamento de cursos de pós-graduação. Recuperado em 15 fevereiro, 2011, de http://www.capes.gov.br/sobrea-capes/legislacao/2341-resolucoes

Reynolds, M. (1997). Towards a critical management pedagogy. In J. Burgoyne \& M. Reynolds (Eds.), Management learning: integrating perspectives in theory and practice (pp. 312-328). London: Sage Publications.

Reynolds, M. (2009). Wild frontiers reflections on experiential learning. Management Learning, 40(4), 387-392. doi: 10.1177/1350507609335848

Reynolds, M., \& Vince, R. (2004). Critical management education and action-based learning: synergies and contradictions. Academy of Management Learning \& Education, 3(4), 442-456.

Romm, N. (2002). A trusting constructivist approach to systemic enquiry: exploring accountability. Systems Research and Behavioral Science Journal, 19(5), 455-467. doi: 10.1002/sres.501

Schön, D. A. (1983). The reflective practitioner. New York: Basic Books.

Schwandt, T. A. (2000). Three epistemological stances for qualitative inquiry. In N. Denzin \& Y. Lincoln (Eds.), Handbook of qualitative research (pp. 189-213). Thousand Oaks, California: Sage Publications.

Vergara, S. C. (2009). Métodos de coleta de dados no campo. São Paulo: Atlas.

Vince, R. (1995). Emphasizing learning in management research. Management Learning, 26(1), 5571. doi: $10.1177 / 135050769502600104$

Williamson, A. (1997). Reflection in adult learning with particular reference to learning in-action. Australian Journal of Adult and Community Education, 37(2), 93-99. 